\title{
Dr P R Walpita - Paediatric Surgeon
}

MBBS (Ceylon), FRCS (Edin.), FRCS (Eng.)

Sri Lanka Journal of Child Health 2008; 37: 31-32

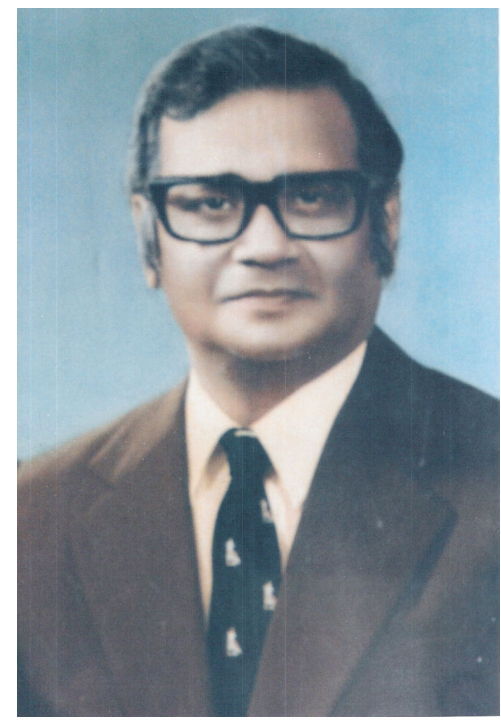

Dr P R Walpita, who passed away at the age of 82 years, was a well known paediatric surgeon. He received his early education at St. John's College, Panadura and later at Royal College, Colombo. At Royal College he excelled in studies as well as sports, representing the school in boxing (at the Stubbs Shield) and rugby.

He graduated MBBS (Ceylon) in 1946 and after serving in many parts of the country, proceeded to the UK for postgraduate studies in 1951. While in the UK he obtained the fellowship of the Royal College of Surgeons (Edin.) and the Royal College of Surgeons (England). During this period he worked at Walton Hospital, Liverpool, St James Hospital, Balham, and at St. Luke's Hospital, Maidenhead, London.

He returned to Sri Lanka (then Ceylon) in 1955 and functioned as a surgeon in many parts of Sri Lanka. He participated in the $1^{\text {st }}$ Asian Gastroenterological Congress in Tokyo in 1960 and another in Chandigarh in 1962. During the period 1961-62 he was a Nuffield Foundation Research Fellow in cardio-vascular surgery in the UK attached to St Mary's Hospital, London. On his return he was appointed as paediatric surgeon, Lady Ridgeway Hospital (LRH), Colombo and was promoted as consultant paediatric surgeon in 1969. The 1960's were the formative years of paediatric surgery at LRH; his colleagues were Professor Milroy Paul, Professor M V P Peiris (both part-time) and Dr F A Sandrasagara. They were the pioneers of paediatric surgery in Sri Lanka, running two units. At present, there are many paediatric surgical units in Sri Lanka; 4 at LRH, one each in Kandy, Peradeniya, Karapitiya and at Sri Jayawardenapure Hospital, Kotte. There is a total of 13 paediatric surgeons in Sri Lanka at present.

During this period he kept in touch with advances in his speciality by participating in conferences such as the World Cardiological Congresses in Stockholm and New Delhi, Afro-Asian Paediatric Congress in Karachchi and the centenary celebrations of the Royal Children's Hospital in Melbourne, Australia. In 1971, he was elected President of the Sri Lanka Paediatric Association (predecessor to the Sri Lanka College of Paediatricians) and became a member of the British Association of Paediatric Surgeons. In 1972 he had the rare privilege of becoming a Senior Commonwealth Fellow in paediatric surgery and worked with $\mathrm{MrH} \mathrm{H}$ Nixon at the Hospital for Sick Children, Great Ormond Street, London, where I used to meet him frequently whilst researching. During this period he attended Professor Fritz Rehbends Kinder Clinic at Bremen, Germany, the surgical unit at Alder-Hey Hospital in Liverpool, the paediatric surgical clinics of Professor Gunner Grobe at Uppsala, Sweden and Professor Th. Ehreupeis clinic at the Karolinska Institute, Sweden. Upon his return, he was appointed senior consultant paediatric surgeon in which post he remained until he retired in April 1978. During the 1970's I was closely associated with him in jointly managing very complicated cases. I am personally aware of his dedication to work. In these years void of private practice he used to work long hours and spend his own money to purchase expensive medications for the benefit of poor patients. These poor patients were blissfully ignorant of their anonymous benefactor! In 1976, he visited the Peoples Republic of China as a member of an official delegation and lectured at the Peking Children's Hospital and at the Shanghai Children's Hospital. After his retirement he 
functioned as a consultant surgeon at the New General Hospital, Kaduna, Nigeria till his return to Sri Lanka in 1994. In 1997 he was awarded the Fellowship of the Sri Lanka College of Paediatricians in its inaugural year.

Dr Walpita was an excellent teacher and the undergraduates like us as well as postgraduates were the beneficiaries. I remember very vividly how I attended Dr Walpita's ward round at LRH in 1966, when I should have been assisting Professor R A Navaratna in the operating theatre, for which I was duly punished!! He examined at the Final MBBS and DCH examinations. Dr Walpita had many publications to his credit, both in local and international journals such as the British Journal of Surgery, Journal of Paediatric Surgery and the Archives of Diseases in Childhood (where I was a coauthor). Latterly he led a very spiritual austere life, spending many hours in deep meditation.
Dr Walpita hailed from an illustrious family from Horana. One brother (PGW) was a group captain in the Sri Lanka Air Force, another (SWG) a judge of the Supreme Court as well as another brother (SJW) who was a civil servant, vice-chancellor and an ambassador. He is survived by his wife, son, daughter and grand-daughter.

May he attain the supreme bliss of Nirvana!

\section{Sanath P Lamabadusuriya}

